Abstracted by George Howard Parker, author Harvard University.

The crawling of young loggerhead turtles toward the sea.

Newly hatched loggerhead turtles find their way from their nests to the sea in consequence of at least three factors: first, positive geotropism, as shown in their tendencies to move down slopes; second, their response to their retinal images, in that they move toward regions in which the horizon is open and clear and away from those in which it is interrupted by complicated masses, and, third, their probable response to color, in that they move toward blue areas rather than toward those of other colors (Hooker). These animals are not appropriately described as phototropic, for they do not move either toward a source of light or away from it, but they are to be regarded as exhibiting a more complex condition in that they respond to the details of their retinal images rather than to these images as wholes. 


\title{
THE CRAWLING OF YOUNG LOGGERHEAD TURTLES TOWARD THE SEA
}

\author{
G. H. PARKER \\ Zoölogical Laboratory, Harvard University
}

It is difficult to imagine a more striking and invariable reaction among higher animals than the crawling of newly hatched loggerhead turtles (Caretta caretta Linn.) toward the sea. For a long time this response has excited the interest of field naturalists, and within recent years it has been studied with especial care by Hooker ('08 a, '08 b, '09, '11) and commented upon by Mayer ('09, p. 121). To see a dozen of these newly hatched creatures, that have had no previous experience with the ocean, scramble toward it, notwithstanding that it may not be within the range of their vision, is a sight never to be forgotten. Any attempt on the part of an observer to check them in their course seems only to excite them to further effort which does not cease till they have reached the water. To the observer they seem to be drawn toward the sea by an influence as mystical as it is impelling.

On July 5 th a considerable number of these turtles were hatched at the Miami Aquarium, Miami Beach, Florida, and it was here that I had an opportunity of studying their reactions not only on the day of hatching, but also over a subsequent period of a week or so. My thanks are due to the officers of the Miami Aquarium Association for the privilege of working at the aquarium laboratory and for their generosity in providing me with all that was necessary for my investigations.

After my attention had been called to the remarkable regularity with which the young turtles on the aquarium wharf went toward the water, I began some more or less systematic observations and experiments. A piece of smooth paper-board, about a meter square, was laid down horizontally on the wharf and surrounded on all four sides by a low wooden fence some $15 \mathrm{~cm}$. high. At the 
middle of the pen thus constructed turtles were liberated one at a time and with their heads pointed in sequence north, east, south, and west. The water and the late afternoon sun were both to the west and the turtles almost without an exception took that course.

To ascertain whether the sun or the water was the effective element in the situation, I carried the paper-board and about a dozen turtles across the narrow key on which the town of Miami Beach is situated to the opposite shore. Here the water was to the east while the sun of course remained in the west. On resetting the pen on the beach and liberating the turtles as before at its center, they were found to go as regularly to the east, i.e., toward the water, as they had previously gone to the west. It was therefore plain that the sun had no significant influence over their movements, but that these were related to the body of water.

On my return from the ocean on the east side of the key to the bay on the west side I stopped in a field about midway between the two bodies of water, and having set up the pen here with its floor horizontal, I proceeded to a third set of tests. I was greatly interested to see that under these circumstances the turtles were not disposed to move much from the center of the board and that when they did move they were as likely to go in one direction as in another. During these tests the sun was still high in the western sky and the results showed again that this source of light was not a significant factor in determining the direction of motion. Not only did these observations demonstrate that the sun was ineffective, but they showed also that the water, at least at the distance of about a quarter of a mile, was also ineffective, for the turtles went as often to the north or the south as they did to the east or the west. Had they been under the influence of the water, they should have turned even in this intermediate position to the east or the west, but not to the north or the south. Apparently the middle of the key was a region in which the turtles were as indifferent to the influence of the water as they were in all places to that of the sun. So far as the sun is concerned, my observations agree entirely with those of Hooker, who declared both in 
his preliminary ('09, p. 124) and in his final report ('11, p. 70) that the sun has nothing whatever to do with the direction in which the turtles creep.

During these preliminary trials it became perfectly evident that the young turtles were very responsive to the slope of the surface upon which they moved; in other words, that they were geotropic to a marked degree. Care was therefore taken that the paper-board on which the tests were carried out was always horizontal and attention was given to the geotropism of the turtles as such. In all my experience the young loggerhead turtle was always positively geotropic. It regularly goes down slopes, notwithstanding the fact that it has ample energy and strength to go up them, and it is responsive to even so slight an inclination to the horizontal as $10^{\circ}$. On more considerable inclinations the animals go down with a rush. Hooker ('11, p. 72) states that "under ordinary circumstances the young turtles are negatively geotropic, but if the possible descents have been exhausted, they become positively geotropic." As a descent is evidence of positive and not negative geotropism, Hooker has apparently confused terms and, if this is so, his observations agree with mine except that I have never seen any evidence whatever of negative geotropism (movement against gravity). In all my tests of turtles from the time of their hatching till the end of their first week of life, they have been consistently positive in their geotropism. When placed on the natural slope of a beach, even though they cannot see the water, they travel downward at a considerable rate.

How they escape from the shallow nest in which they are hatched I do not know, for I have never had the opportunity of studying them under these circumstances. Newly hatched turtles in the laboratory were from thebeginning always positively geotropic, so that I have no reason to believe that there is any change in their geotropism. Such nests as I have seen were always shallow, and it is quite possible that turtles on hatching pass up their slopes and over their rims under other influences than those having to do with geotropism and thus escape. But concerning the details of this question I have no facts to offer. 
In all the tests I carried out, as already stated, the turtles were uniformly positively geotropic.

Having determined that young turtles are positively geotropic, I next turned my attention to their responses to water. That they are not directed in their movements by water vapor in the air, by the smell of water, or of materials associated with it, or by the sound of waves, etc., has been abundantly shown by Hooker ('11), and on these points I can confirm practically all his statements. If next a course over which young turtles are making their way toward the sea a shallow vessel of water is placed so that they might enter it, they pass it by without showing even a deflection in their line of march. Had the water in itself possessed a quality attractive to the turtles, some change in their course would certainly have been evident. That water does not thus attract them is also evident from the fact that turtles liberated in the pen on the laboratory wharf in the darkness of night did not move toward the water as they did in the daylight, but crept about indiscriminately.

If water in itself does not influence the direction of movement of the young turtles and if sources of light, such as the sun, are equally ineffective in this respect, what is the factor that determines the course that they take on a horizontal surface? When turtles were liberated at the center of the horizontal pen already described as set out on the laboratory wharf and their courses toward the water were closely observed, it was found that these courses were not directly toward the water, which was almost exactly west, but they were a little to the north of west. When the surroundings were inspected to ascertain what might be present to cause this peculiarity, it was seen that the main mass of the aquarium building loomed up a little to the south of east from the pen and that if a straight line was drawn from this mass through the center of the pen westward it would point to a very open unobstructed horizon. Such a line included the course taken by the turtles. It therefore seemed possible that the young turtles took a course which led away from the most considerable mass upon the horizon and toward the most unobstructed and open parts of that line. To test this view I tried an experiment 
almost exactly like that described by Hooker ('11, p. 72) in that I set up the horizontal pen in an open field to the east of a low hedge west of which was a sea-wall and the bay. On liberating the turtles here they all took easterly courses away from the hedge, and incidentally away from the water. Their courses were toward the open field. Evidently, the mass of the hedge and the open field influenced the direction taken much as the laboratory buildings and the open water had done, but in this instance it was perfectly evident that the water had no necessary part in determining this direction. These results agree exactly with those obtained by Hooker.

I next set up the pen in a square open field, three sides of which were bounded by well-grown trees and the fourth fairly open. The turtles went with reasonable regularity toward the open side. I then transferred the pen to a very open sandy plane and piled up next one side of it a number of boxes and tin cans till a wall nearly a meter high was formed. From this the turtles regularly moved away. These various tests led me to conclude that any large mass interrupting the horizon forms a center from which young loggerhead turtles retreat.

But these animals not only retreat from conspicuous masses on the horizon; they also move toward the open horizon with great certainty. I was persuaded of this by an accidental observation made while I was testing a very different matter. I had placed the horizontal pen between and in front of two well-grown bushes to ascertain whether the turtles would orient to one or other of these or give a combined reaction to both. Much to my surprise the turtles did not retreat from the bushes, but took a course in the opposite direction as though they were going directly through the opening between the bushes. On looking through this opening I observed what had escaped my attention before, a considerable stretch of free horizon. I repeated this test several times and always with the same result, the turtles took a course between the two bushes. Consequently, I concluded that though young loggerhead turtles move away from large interrupting masses on the horizon, they also move with great certainty toward a section of open horizon even though this may be relatively small. 
In a final set of experiments designed to test the effects of the overhead and the horizontal fields of light, I had an excellent opportunity to observe the exact method of response of the turtles to their illuminated surroundings. Two large collecting tubs were placed upon a sea-wall, one right side up and the other bottom up. The tubs had a diameter of about $50 \mathrm{~cm}$. and a height of a little over $30 \mathrm{~cm}$. Five turtles were tested by being placed alternately on top of the inverted tub at its center and inside the upright tub likewise at its center. From the top of the inverted tub the turtle could see the whole landscape; from inside the upright tub it could see only the overhead sky. From both positions the turtles were free to move in any horizontal direction. In each set of tests a given turtle was headed successively north, east, south, and west. The sea-wall on which the tubs were set ran approximately north and south; to the west was open water; to the east a field with trees and shrubbery. In the twenty tests inside the tub the turtles remained stationary for five minutes in fourteen instances and in the remaining six they took various courses which may be roughly described as twice to the northwest, twice to the east, once to the northeast, and once to the southwest, showing that the overhead sky had no effect on their orientation. In the twenty tests on the outside of the tub the turtles went invariably to the west, away from a horizon interrupted by trees and shrubbery and toward one of open water. But the interesting part of these tests was not so much the direction taken by the turtles as the way in which this direction was apparently discovered. When the young turtle was set at the middle of the inverted tub, it rested there quietly about half a minute, raised its head high in air, made a complete circle or more in a very restricted area, and then moved off immediately to the west. The preliminary circular movement, almost always a complete circle or more, was made irrespective of the position in which the turtle was set. To all appearances it seemed as though the animal tested first the whole horizon and then moved in a direction away from large masses and toward greatest openness.

In describing the photic responses of the young loggerhead, Hooker uses the terms photophilism and phototropism ('11, p. 71) 
without, however, making very clear what is meant by these, and finally concludes that, though the animals are not influenced in their movement by the sun, they are nevertheless positively phototropic ('11, p. 75). He compares them with certain positively phototropic animals studied by Cole ('07) in which responses to the area of illumination rather than to the intensity of the light was the determining factor in their locomotion. In my own tests on the turtles I have never seen any evidence that they are, strictly speaking, phototropic. Thus I have never been able to get a turtle in a dark room to creep toward a light such as happened with all the animals tested by Cole. Hence I think it improbable that the young loggerheads are correctly described as positively phototropic. To me they seem to be an example of a much more complicated set of relations than those seen in phototropism. Their retinal images are immensely complex as compared with those in many of the lower forms, and they respond more to the details of these images than to the images as wholes. That part of the image which represents the region of the horizon is much more important in determining the direction of locomotion in the young turtle than any other part. If a portion of the horizon is interrupted by many masses rich in detail, such as trees, shrubbery, houses, etc., it may form a center from which the turtle will move away. If a portion of the horizon is uninterrupted and very uniform, as where sea and sky meet, that part may form a center toward which the turtle will go. These conditions indicate that the details of the retinal image in the turtle are the significant features in determining the direction of its creeping rather than the image as a whole and that consequently the turtle possesses a kind of vision more like that in the human eye than like that in the eye of purely phototropic animals, even if we include among these the peculiar instances pointed out by me ('03) and by Cole ('07) in which the size of the illuminated area is as significant as the intensity of the light.

Hooker's contention ('09; '11, p. 74), that turtles move toward blue rather than toward other colors and thus reach the sea, may perfectly well be correct. When I made my tests I unfortunately had no adequate means of experimenting with colors, and con- 
sequently I am not in a position to add anything to this aspect of the subject. I am nevertheless convinced that beside color the photic complexity and photic simplicity of the region of the horizon, as has already been detailed, are factors of first importance in determining the direction of locomotion, for in a number of my tests, as for instance those in the open field, natural blues even in the sky were often absent. Hence I conclude that, quite aside from the effect of color, the direction of locomotion of young loggerhead turtles is significantly influenced by the interruptedness or openness of the region of the horizon.

On beaches locomotion down a slope, away from an interrupted horizon and toward an open one, as well as toward masses of blue, would almost invariably lead to the sea. These doubtless are the chief factors that influence the course of the newly hatched loggerhead turtle whereby it reaches the ocean. Although water is the environment to be attained, water in itself plays no part in directing the movements of this animal which are indirectly influenced by those features of the environment just enumerated. It would be interesting to ascertain whether any of these factors affect Fundulus in its escape over the beach to the sea from small pools as described by Mast ('15).

\section{CONCLUSIONS}

Newly hatched loggerhead turtles find their way from their nests to the sea in consequence of at least three factors: first, their positive geotropism as shown in their tendencies to move down slopes (Hooker); second, their response to their retinal images in that they move toward regions in which the horizon is open and clear, and away from those in which it is interrupted, and, third, their probable response to color in that they move toward blue areas rather than toward those of other colors (Hooker).

These animals are not appropriately described as either negatively or positively phototropic, but are to be regarded as exhibiting a more complex condition, in that they respond to the details of their retinal images rather than to these images as wholes. 


\section{LITERATURE CITED}

CoLE, L. J. 1907 An experimental study of the image-forming powers of various types of eyes. Proc. Amer. Acad. Arts Sci., vol. 42, pp. 335-417.

Hooker, D. 1908 a The breeding habits of the loggerhead turtle and some early instincts of the young. Science, vol. 27, pp. 490-491.

$1908 \mathrm{~b}$ Preliminary observations on the behavior of some newly hatched loggerhead turtles (Thalassochelys earetta). Yearbook Carnegie Inst., Washington, no. 6, pp. 111-112.

1909 Report on the instinets and habits of newly hatched loggerhead turtles. Yearbook Carnegie Inst., Washington, no. 7, p. 124.

1911 Certain reactions to color in the young loggerhead turtle. Papers Tortugas Lab., Carnegie Inst., vol. 3, pp. 69-76.

MAST, S. O. 1915 The behavior of fundulus, with special reference to overland escape from tide-pools and locomotion on land. Jour. Anim. Beh., vol. 5, pp. 341-350.

MAYER, A. G. 1909 Ann. Rep. Director Dept. Marine Biol. Yearbook Carnegie Inst., Washington, no. 7, p. 121.

PARKer, G. H. 1903 The phototropism of the mourning-cloak butterfly, Vanessa antiopa Linn. Mark Ann. Vol., pp. 453-469. 